\title{
SERVICE LEARNING AND TEAM WORK - ELEMENTS OF LEADERSHIP
}

\author{
Dena W. McMartin \\ Faculty of Engineering and Applied Science, University of Regina, Canada. \\ dena.mcmartin@uregina.ca
}

\begin{abstract}
In a senior undergraduate course, collaboration between the Environmental Systems Engineering (EVSE) program and Facilities Management (FM) was initiated to provide support to the campus and valuable learning and leadership opportunities for students. A list of potential projects related to the curriculum was developed in consultation with FM employees, the President's Advisory Committee on Sustainability (PACS), and EVSE. The intent of the team projects is to support the strategic plan goals set out by the University of Regina and Faculty of Engineering and Applied Science by providing high quality, timely educational opportunities with practical, immediate, and sustainable recommendations. The projects and approach to project management include significant elements of leadership, organization and management, communications, and engineering application. Students were provided with project ideas encompassing weighty challenges aligning the interests and expectations of FM and EVSE to result in both short-term and long-term impacts and benefits. In an era of cost-cutting and budget constraints in higher education, the projects allow students the opportunity to provide meaningful recommendations that stretch their engineering and leadership skills while supporting vital evaluation, efficiency and design improvements, and environmental systems analysis incorporating best practices of economics, public attitudes, environmental and public health, team work and management, and communications. Student feedback indicates a high level of satisfaction with the concept of service learning on campus and improved team work and leadership skills development over the course of the semester.
\end{abstract}

Keywords: Service-Learning, Team Work, Project Management, Student Engagement

\section{INTRODUCTION}

The use of teaching and learning models that focus on supporting development of problem solving skills, team work and leadership abilities, and project management applications are essential in the creation of engineers for society. Regardless of discipline or practice, communication skills and the ability to recognize and leverage strengths and to recognize and address weaknesses help engineers to become more active, more confident and more connected to their work.

Numerous benefits are available to instructors who incorporate active and collaborative learning models in the classroom, as student learners gain the confidence required to function in their academic and professional careers.

Financial pressures on PSE institutions to recruit and retain students in an economic climate such as that currently existing in Saskatchewan lend themselves well to service-learning projects that engage students in meaningful interactions within their community, including potential employers. Indeed these pressures on higher education, such as changing demographics, competition for youth, increase in degree-granting colleges, and changing expectations and opportunities in workplace and workforce can result in more innovative and active teaching and learning scenarios as PSE institutions work to maintain relevance and to retain those students enrolled.

Service learning projects support engineering education through enhancement and confirmation of context and relevance of classroom learning and extend these into experiential learning in the classroom and beyond. These serve numerous benefits including student recruitment and retention in PSE, but also in the constructing and honing of problem solving skills. Using service-learning projects in the teaching and learning model for a course increases student engagement on current issues, demonstration and application of knowledge and skills introduced in the course content, and introduction of 
students to connections and interactions with previous course work.

Methods for coordinating and evaluating service-learning projects in the Environmental Systems Engineering program at the University of Regina included modification of project templates from the business education model. These systems were then implemented in a senior engineering course ground truthing and subsequent revision for future use. Here, students were engaged in on-campus service projects requiring elements of problem solving and design recommendations. The results from these experiences were used to modify teaching and learning approaches as well as the project design and templates themselves. All modifications and revisions to documentation processes and intended outcomes were implemented to better engage and demonstrate engineering approaches to problem solving and perspectives in the final products.

A senior engineering course for implementation was chosen as a vehicle for evaluating service-learning methods via for achieving several benefits and outcomes including: 1) project management, 2) leadership and team work, 3) professional communications and network development, 4) problem analysis through application of theory, skills and knowledge, and 5) applied research on the impact of engineering decisions on society and environment. Students have the opportunity to demonstrate their body of knowledge and abilities in a team atmosphere and discover and enhance their leadership skills and work ethic. Further, this approach provides a more active learning environment that accentuates relevance of course curriculum and the importance and application of the course material.

\section{CLIENTAND STUDENT OUTCOMES}

\subsection{Project Selection}

Arrangements were established to provide support and networking for project selection with both external corporations whose goals are related to the promotion of sustainable infrastructure development and internal departments and units responsible for effective and efficiency operations of campus infrastructure. Further projects are solicited from local industry, particularly those in close proximity who are working on issues wellknown in the media and/or as related to new lines of business or expansions of existing lines.

Regardless of chosen approach, project ideas were solicited from a variety of clients, compiled and prioritized. Under the service-learning approach, a large list of possible projects from 2 or 3 clients was assembled, with only one student group permitted to work on any one project. In this case, clients were provided with single-source outcomes to a diverse set of defined problems.

\subsection{Client Expectations and Requirements}

This teaching and learning model depends heavily on development and maintenance of the client relationship. Deviations from the carefully set expectations of the client-student relationship can quickly erode students' confidence and understanding of the desired product and outcomes.

Clients are required to attend class to present project ideas to the students and allow for initial discussion and agreement on the scope of the chosen endeavour. Students are encouraged to interact with clients throughout the semester, gathering data and information, making connections and digging more deeply into the source and importance of the project.

\subsection{Student Expectations and Requirements}

Through this teaching and learning model, there is an opportunity to directly apply theories and methods from class to project development, design, and approach. Further, a direct link between the course material and service-learning projects is created, which keeps both students and instructors on target. Within this, there is a need to ensure that instruction does not focus solely on the assignment but continues to deliver to full range of curricular requirements. This approach tends to build stronger teamwork elements and allows for the instructor to mentor students through the process more effectively and in a more focused manner.

There are four project deliverables throughout the term that students are required to deliver: 1 ) project memo including specific project scope, 2) client presentation, 3) final report, and 4) project management documentation (submitted at least twice in the semester as an indicator of progress). While corresponding deadlines ensure that students manage their time appropriately throughout the term, the deliverable schedule also provides opportunities to learn from feedback provided by the instructor, fellow students and the client in a timely manner, and thereby increase student learning and improve final report quality for clients. Because students interact with real clients, necessities of professionalism (consisting of preparedness, communication, and dress) are outlined prior to relevant classes.

2.3.1 Project Content. Students investigate, analyze, and design a solution to the real life opportunity or problem presented by the client using the tools of their profession. To keep students engaged, it is important to clearly 
identify how material taught in class relates to the project on a regular basis.

2.3.2 Project Management. Students are divided into groups and provided with advice on team dynamics, cultural differences, and how to work efficiently and communicate effectively as a group. Teams are required to hold regular meetings and take minutes at those meetings documenting, at a minimum, major decisions made, tasks assigned and their corresponding due dates. As would be typical in consultancy billing, individual students are required to keep record of their own activities including tasks completed, when they were carried out, and how long was spent on each.

2.3.3 Team Leadership. Twice in the semester students are asked to assess themselves and their teammates using two techniques: (1) SWOT analysis from which personal and team results are shared for discussion within the team and (2) group forming status analysis from which the team deciphers at which stage in the "forming-stormingnorming-performing” stages of group development they are in, who their leader has become and if that will continue to be acceptable for team success and harmony, and how they plan to proceed to the next steps in teamwork and project completion.

Team leaders are responsible for not only setting meetings and agendas, but also assigning and completing tasks, holding to account all team members, setting goals for completion (using a variety of project management tools), and addressing disharmony within the team. Depending on project style and data requirements, team leaders are also required to determine whether or not research ethics approvals are required to ensure that information collected from people via interviews and surveys meet the ethical and legal requirements for managing data and personal information.

\section{SERVICE-LEARNING PROJECTS: RESULTS AND DISCUSSION}

The inaugural service-learning projects were conducted in service of the University of Regina campus, focusing on Facilities Management (the department responsible for construction and maintenance of buildings and campus operations); Health, Safety and Environment department (responsible for safety training, occupational health and safety licencing and reporting, and environmental sustainability); and the President's Advisory Committee on Sustainability (an interdisciplinary council engaged with whole campus activities, outcomes, and goalsetting).
Projects were identified through consultation with engineers and scientists from these groups, focusing primarily on the FM department culminating in a list of 25 possible on-campus service-learning options.

Members of the client groups were not invited to engage formally in class until the completion of projects at which time students presented their findings in professional presentations. However, clients were informally engaged throughout as sources of data and other information, providers of tours and networking, and supporters of identifying off-campus and regulatory connections in support of project completion.

Students were solely responsible for setting the scope of their projects following personal communication with client groups and stakeholders. The scoping process was intended to support learning by demonstrating the importance of setting early goals and limitations to adequately define intended project outcomes and impacts.

In the service-learning projects, a competitive environment was not established. Rather, all student groups (19 in total) conducted research and formulated responses and recommendations for 19 unique projects.

\subsection{Client Outcomes}

Lessons learned in the client-based project competition were applied for the service-learning projects in that client feedback and interaction at the draft report stage was not permitted. As noted, only informal interactions between clients and learners were included in the servicelearning model, thus limiting expectations but also placing more emphasis on information provided by the clients in the final analyses.

Clients' satisfaction was very high in response to this approach with several new ideas submitted for subsequent courses and new on-campus clients requesting to be involved in future. Client feedback included statements such as, "I was really impressed with the level of student research and creativity demonstrated in their final report and presentation" and "The student presentations were exceptional”. So pleased were the clients that word quickly spread across campus and into engineering professional and industry associations who have expressed interest in supporting future endeavours.

All final reports were submitted to the clients and also posted at the University of Regina Archer Library searchable database for public access and review.

\subsection{Student Outcomes}

Students were surveyed at the completion of the course using a survey including 30 Likert-scale statements on a 
5-point scale and 4 open-ended questions where students were asked to comment on their experience throughout the project. The results of the Likert-scale survey statements are based on the responses of 40 students ( $n=$ 40), where 1 indicates little to no agreement and 5 indicated high agreement.

Students indicated that they enjoyed the project (4.05 \pm 0.85 ) and garnered significant satisfaction from working on a real-world problem relevant to their university campus ( $4.70 \pm 0.45)$. Further, the general consensus amongst the students was that they preferred choosing a project from a defined list rather than defining their own project ( $4.4 \pm 0.75$ ); they further agreed that they prefer providing a service likely to have impact within their campus $(4.01 \pm 1.05)$ than a theoretical or thoughtexperiment style approach. Feedback also indicated that the students agreed that the project was well-linked to course content ( $4.05 \pm 0.87$ ). However, learners loosely indicated a need for improved definition of project goals by the instructor.

The minority of students indicated that they had experienced undue hardship finding time outside of lecture hours to meet and plan their project activities and task lists (2.55 \pm 0.43$)$. General agreement was noted regarding the tasks associated with project management and consultancy, such as taking and maintaining notes, meeting minutes, task lists, and timesheets amongst the groups (4.07 \pm 0.88$)$. However, some students did comment in the open-ended section of the survey that they only completed the internal group reporting documents for submission to the instructor, not during the course of the project work itself.

Questions specifically evaluating the importance and appreciation for conducting "service" projects for the University of Regina demonstrate that students highly value the sense of accomplishment and service to their community (4.62 \pm 0.48$)$. Learners also highly value the opportunity to practice their presentation skills ( $4.42 \pm$ 0.68 ) and understand that this practice is essential for demonstration their hard work to the instructor and clients alike (4.16 \pm 0.81$)$. Finally, the students clearly indicate that they value the opportunity to interact with clients as part of the learning process in becoming a professional engineer ( $4.56 \pm 0.48)$.

Comments from students indicate overall satisfaction, pride and a sense of accomplishment. However, as in all things teaching and learning, some comments reflected that not all outcomes were positive outcomes. Challenges related to group work and team member motivation, in particular, were noted indicating a need for increased focus on leadership skills and project management that depersonalizes processes and effects a more consistent and accountable outcome where all students feel they've been treated fairly and equitably. That is, with appropriate skills for handling challenging situations through leadership and communication skills, it is likely that these challenges related to team member interactions can be mostly addressed.

The majority of students were satisfied with being assigned teammates making comments such as, "team mixing is awesome; it gave us a chance to get to know each other and learn from each other". Three students did not agree with the majority, stating that, "I've been here for 4 years and I know who I work best with" and similar statements. As a question of course design and intended student outcomes (e.g., learning to work in diverse teams to solve problems, addressing communication challenges and setting goals together), it is not likely that such a change will be made to team identification. However, additional focus on elements of successful team work will be added.

Both student and client satisfaction levels were very high in response to this coordinated service-learning experience. Lessons learned indicate that the approach is best applied in senior courses where students are both intrinsically and extrinsically motivated and have more self-aware regarding their strengths and weaknesses. Client expectations are such that senior students have the abilities and knowledge to address holistically the questions posed, including submission of high quality final reports that contain reasonable and achievable recommendations.

\section{CONCLUSIONS}

Ground truthing at the University of Regina regarding approach to the design and delivery of service-learning projects indicate significant potential for application within the burgeoning SK resource economy. In fact, response from the engineering community via word-ofmouth has been exceptionally positive and supportive, to the point of industry associations offering not only project ideas but financial support. Inroads have been made within the potash mining sector, in particular, with anticipation of using the client-based project competition method.

Implementing service-learning models can allow for emphasis of key course components, theories, and applications. In changing environments - economically, climatologically, and industrially - student learning must also change and adapt. Opportunities to apply new knowledge and ideas in the classroom and beyond must 
be leveraged to offer student learners a chance to test their potential and increase their network. Instructors must recognize that these methods require much attention to build and maintain client relationships, manage expectations of both students and clients, and ensure that learning outcomes are achieved by effectively linking lectures, laboratories, and project work.

Future student work will focus on both service-learning and client-based projects that highlight and demonstrate concepts related to quantification of sustainability, cumulative effects assessment, proxy environmental baseline development, and risk assessment and mitigation for engineering projects in which complex and extensive environmental impacts are known or expected.

\section{Acknowledgements}

Thank you to the President's Teaching and Learning Scholar program at the University of Regina for funding and support. Involvement from University staff in Facilities Management; Health, Safety, and Environment; the President's Advisory Committee on Sustainability; and the Institute for Energy, Environment and Sustainable Communities is greatly appreciated. Thank you also to student researchers and service providers in the ENEV 422 course who worked diligently to meet their project requirements, ethical review and behavior expectations, and client needs. 